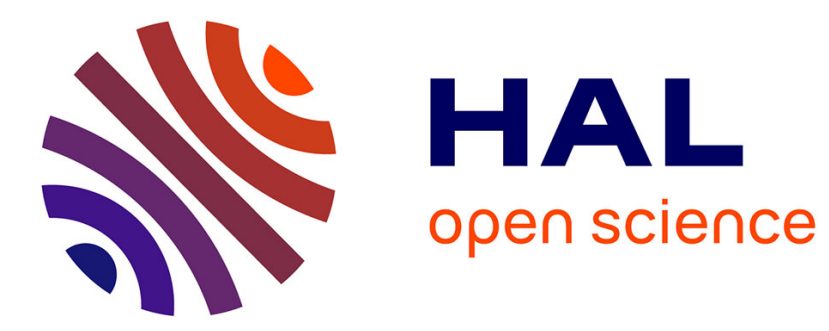

\title{
Passive electro-optic antenna using polymer material
} Arnaud Gardelein, Sylvain Le Tacon, Eric Tanguy, Nicolas Breuil, Tchanguiz Razban

\section{To cite this version:}

Arnaud Gardelein, Sylvain Le Tacon, Eric Tanguy, Nicolas Breuil, Tchanguiz Razban. Passive electrooptic antenna using polymer material. Electronics Letters, 2007, pp.1049. hal-00934680

\section{HAL Id: hal-00934680 \\ https://hal.science/hal-00934680}

Submitted on 4 Feb 2014

HAL is a multi-disciplinary open access archive for the deposit and dissemination of scientific research documents, whether they are published or not. The documents may come from teaching and research institutions in France or abroad, or from public or private research centers.
L'archive ouverte pluridisciplinaire HAL, est destinée au dépôt et à la diffusion de documents scientifiques de niveau recherche, publiés ou non, émanant des établissements d'enseignement et de recherche français ou étrangers, des laboratoires publics ou privés. 


\section{Passive electro-optic antenna using polymer material}

A. Gardelein, S. Le Tacon, E. Tanguy, N. Breuil and T. Razban-Haghighi

The experimental results of a polymer microwave electro-optic antenna are reported. The device amplitude-modulates an optical input beam with a free-space propagating electromagnetic wave. By using a new dipole printed antenna, the electromagnetic energy is concentrated inside the device. An antenna factor of $168 \mathrm{~dB} / \mathrm{m}$ is achieved with only $1 \mu \mathrm{m}$ of electro-optic polymer.

Introduction: During the past decade, microwave photonics interfaces have been under constant development. These interfaces have many applications, from field sensing to telecommunications networks. Field sensing covers applications such as radar fields cartography, or EMC compatibility measurements for electronic devices. In the telecommunications networks, with the recent emergence of wireless technologies such as Wi-Fi and the growth of related services such as video on demand, there arises a need for a link between wireless networks and high bit-rate networks such as optical fibre ones. Nowadays, this link exists as a combination of many components such as antennas, amplifiers and active microwave photonics devices such as DFB laser diodes or passive components such as electro-optic (EO) or electroabsorption amplitude modulators. A DFB laser diode is bandwidth limited while EO modulators based on lithium niobate present a very high microwave permittivity (28) limiting the sensitivity of the sensor.

In this Letter we introduce a new microwave photonics interface, which can fulfil both purposes. Although the design may be applied to all EO materials, the application we present is based on EO organic polymer. Organic polymers are promising materials owing to their low dielectric constant, frequencies applications up to $100 \mathrm{GHz}$ [1] and the electro-optic coefficient capabilities. At the University of Nantes, the Laboratoire de Synthèse Organique optimised the synthesis of a cross-linkable PGMA/DR1 composite [2] and is able to provide quantities up to $10 \mathrm{~g}$ per synthesis. Therefore we chose this polymer because it is synthesised in our vicinity. We characterised this polymer, and measured a dielectric constant of 4.5 and a maximum electro-optic coefficient of $11 \mathrm{pm} / \mathrm{V}$ [3].

Microwave photonics interface, the electro-optic antenna: The objective of a microwave photonics interface is to amplitude-modulate an optical beam with free-propagating microwave information (E-field amplitude, data). The electro-optic effect is well suited to achieve this objective. Indeed, this effect arises in non-centrosymetric materials; when an electric field is applied the optical index changes. For example, in a uniaxial material such as lithium niobate or organic polymer, when the electric field $E$ is applied along the extraordinary axis, the indices $n_{o}$ and $n_{e}$ become:

$$
n_{o}(E)=n_{o}-\frac{1}{2} n_{o}^{3} r_{31} E \quad \text { and } \quad n_{e}(E)=n_{e}-\frac{1}{2} n_{e}^{3} r_{33} E
$$

where $r_{31}$ and $r_{33}$ are the relevant electro-optic coefficients of the material in this configuration. For an input incident beam polarised at $45^{\circ}$ of the material optical axis, each orthogonal component of the beam is phase modulated. At the output, the combination of both phase modulated components generates a polarisation-modulated beam. This polarisation modulator can be placed in a crossed polarisers setup, thus obtaining an single beam amplitude EO modulator.

To achieve an efficient device, we improved the microwave photonics interaction, represented by the half-wave field $E_{\pi}$ :

$$
E_{\pi}=\frac{\lambda}{\left(n_{o}^{3} r_{31}-n_{e}^{3} r_{33}\right) d}
$$

where $\lambda$ is the incident beam wavelength. Among those parameters, the optical indices and the microwave relative dielectric constant $\varepsilon_{r}$ (implied by the presence of the electric field), are intrinsic to the material and could not be optimised. The electro-optic coefficients $r_{31}$ and $r_{33}$ can be increased by selecting the appropriate material, or by chemical engineering in the polymer case. The optical path length may be also increased by either changing the material length or using optical resonance such as the Fabry-Perot effect. However, we chose the more convenient possibility to decrease the half-wave $E_{\pi}$ by concentrating the electric field in the microwave photonics interaction zone.
Because our device concentrates the free-propagating microwave radiation in a fixed location, we named it an electro-optic antenna.

Electro-optic antenna design: To increase the electric field in the microwave optic interaction zone, we use a dipole antenna printed on a glass substrate. However, there are two slight differences with a classical dipole antenna. First, the two dipole arms are located on each face of a $1 \mu \mathrm{m}$-thick EO polymer layer. Secondly, at the centre of the dipole, the two arms are overlapping on a short length, forming the microwave concentration zone. With those two differences, the received electric field is concentrated in the polymer EO material.

We evaluated the performances of this structure with IE3D, a moment method based microwave 2.5D simulator. Due to the lowest simulator resolution, we computed the results using a polymer thickness of $3 \mu \mathrm{m}$, although the experimental value will be $1 \mu \mathrm{m}$, the highest available thickness. Since polymer thickness is negligible compared to the electrical wavelength, the design basic principle will not change. However, the electric field's computed values will be a lower estimation of the experimental ones.

Simulation results, in Fig. 1, show the dependence of the E-field concentration on the frequency and the overlapping zone length. These results highlight the excellent concentration ratio; with a $1 \mathrm{~V} / \mathrm{m}$ incident plane, the E-field in the interaction zone is up to $3500 \mathrm{~V} / \mathrm{m}$. When the overlapping zone shrinks $66 \%$ from 0.3 to $0.1 \mathrm{~mm}$, the maximum E-field amplitude in the interaction zone increases $230 \%$, and the frequency decreases $4 \%$.

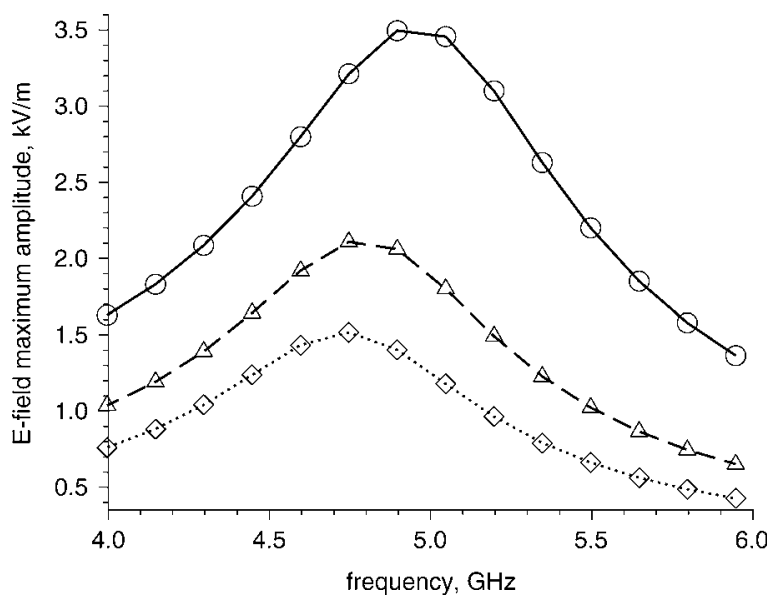

Fig. 1 Simulation results showing maximum electric field amplitude in interaction zone against frequency

Interaction length

$\bigcirc-0.1 \mathrm{~mm}$

$-\diamond-0.2 \mathrm{~mm}$

$\diamond 0.3 \mathrm{~mm}$

Parameters: $20 \mathrm{~mm}$ total dipole length, $0.5 \mathrm{~mm}$ dipole width, $3 \mu \mathrm{m}$ polymer thickness, 4.5 polymer dielectric constant, $1 \mathrm{~V} / \mathrm{m}$ normal incident plane

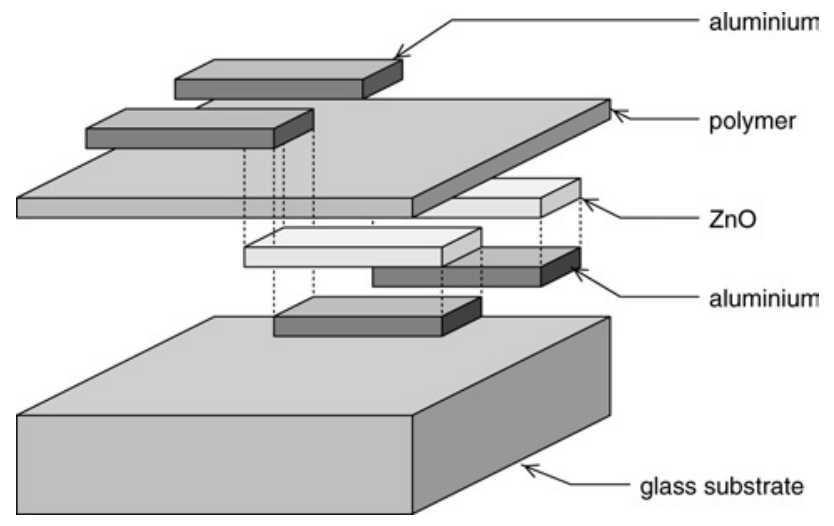

Fig. 2 Prototype expanded view

Dipole $20 \mathrm{~mm}$ long, $0.5 \mathrm{~mm}$ width, conducting layer $1 \mu \mathrm{m}$ thick as well as polymer layer. Glass substrate $1 \mathrm{~mm}$ thick

Although an overlapping zone of $0.1 \mathrm{~mm}$ gives the best concentration ratio, we use a value of $0.3 \mathrm{~mm}$, owing to available technology in our 
labs. To let the optical beam enter in the microwave concentration zone, we replaced the adequate extremity of the bottom arm with a transparent and conducting material such as $\mathrm{ZnO}$. Fig. 2 shows the expanded view of the prototype. Using this configuration, the optical beam is incident to the sample on the back of the glass substrate. The beam goes through the substrate, the $\mathrm{ZnO}$ part of the dipole bottom arm, the polymer layer and reflects back on the aluminium dipole top arm. This polarisation modulator is placed between the crossed polariser to form an amplitude EO modulator. The microwave signal is incident by the other side of the sample.

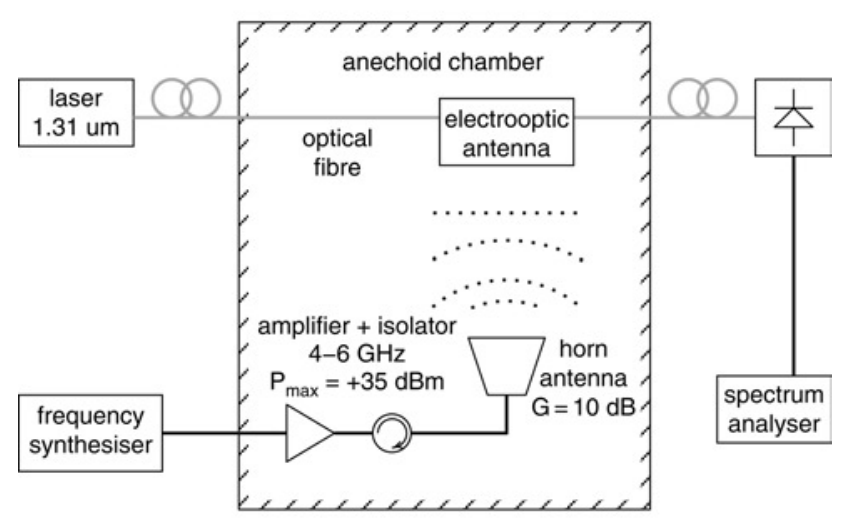

Fig. 3 Prototype test bench

Electro-optic antenna placed at $70 \mathrm{~cm}$ of emitting horn. Electro-optic antenna is passive component: absolutely no electrical contact (neither for power supply, nor for signal) with device

Measurements: To characterise our prototype we set up a test bench as in Fig. 3. This bench contains a microwave part and an optical part. The microwave signal is generated by a frequency synthesiser, then amplified $35 \mathrm{~dB}$ and emitted in the air by a horn antenna of $10 \mathrm{~dB}$ gain. The total emitted power is $45 \mathrm{dBm}$, leading to an incident electric field of $70 \mathrm{~V} / \mathrm{m}$ on the electro-optic antenna placed at $70 \mathrm{~cm}$ of the emitting horn. The microwave bandwidth is $2-6 \mathrm{GHz}$ owing to the amplifier and the isolator. The output microwave signal is measured by a spectrum analyser Agilent A4440, at resolution bandwidth of $1 \mathrm{~Hz}$, enabling a noise level of $-144 \mathrm{dBm}$. The input optical signal, at $1,31 \mu \mathrm{m}$ wavelength for a power of $+13 \mathrm{dBm}$, is generated by a DFB laser. The output optical signal, modulated by the electro-optic antenna, is collected by an amplified photodiode, a New Focus model 1554.

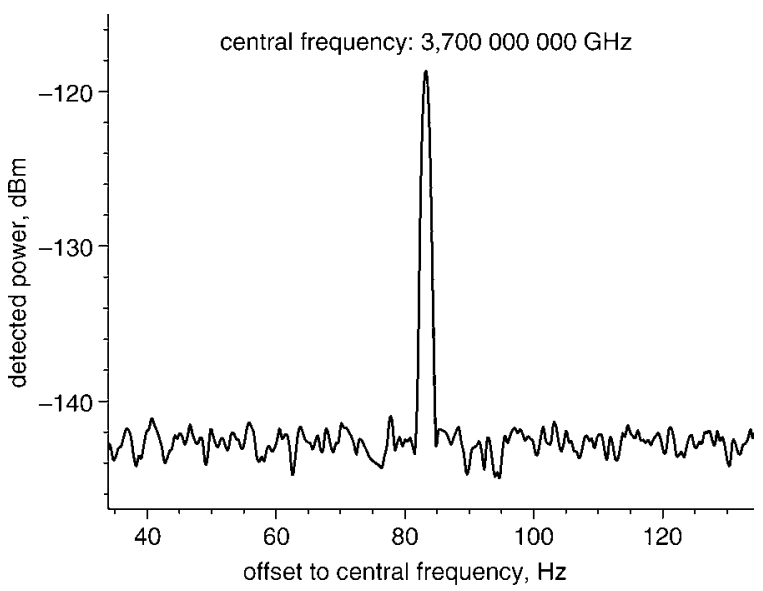

Fig. 4 Measured output signal spectrum at $3.7 \mathrm{GHz}$
To limit direct couplings we moved the sensitive parts (laser, detector and analyser) away from the vicinity of the chamber, at a distance of $40 \mathrm{~m}$. We then measured the output signal in two configurations: using a mirror instead of the electro-optic antenna, and setting the horn antenna polarisation at $90^{\circ}$ of the dipole antenna. In both cases there was no significant perturbations. Finally, we measured the antenna in the optimum configuration. The maximum antenna response is $-118 \mathrm{dBm}$ at a frequency of $3.7 \mathrm{GHz}$, as shown in Fig. 4. Based on those results, we deduce the antenna factor of our device, the ratio between the emitted electric field and the microwave detected voltage. The incident electric field is $70 \mathrm{~V} / \mathrm{m}$, and the output signal is $-118 \mathrm{dBm}$ on a $50 \Omega$ load, leading to a detected voltage of $281 \mathrm{nV}$. The antenna factor is thus $20 \log 70 / 281 \times 10^{-9}=168 \mathrm{~dB} / \mathrm{m}$.

Conclusion: We have presented our first prototype of an electro-optic antenna, a microwave photonics interface which can be used for field sensing applications as well as telecommunications ones. The antenna design is based on a simple structure, a dipole antenna optimised for a thin layer. We built a sample and measured the antenna response using our test bench. The optimum received signal is $-118 \mathrm{dBm}$ at a frequency of $3.7 \mathrm{GHz}$ leading to an antenna factor of $168 \mathrm{~dB} / \mathrm{m}$. This antenna factor is achieved with only $1 \mu \mathrm{m}$ of polymer thickness, and without any electrical contact with the antenna. Using this original design we achieved a contactless electrically passive microwave photonics interface. This structure can be enhanced, either by reducing the microwave optic interaction zone, or by using a waveguide technique for the optical beam propagation.

Acknowledgments: The authors thank A. Scarpaci, E. Blart and F. Odobel from Laboratoire de Synthèse Organique, University of Nantes, for providing the polymer, and N. Barreau and J. Kessler from Laboratoire des Matériaux Photovoltaïques, University of Nantes for depositing the antenna conducting layers. Cookson Electronics, Cholet, are thanked for building the conducting layer mechanical mask, and P. Molina, IRCCyN, Ecole Centrale de Nantes, for building some main parts of the experiment. This work was funded by Thales Airborne Systems and the Région des Pays de la Loire, France.

A. Gardelein, S. Le Tacon and E. Tanguy (Université de Nantes, Nantes Atlantique Universités, IREENA, EA1770, Polytech-Nantes, rue C. Pauc-Bât. IRESTE BP 50609, Nantes F-44000, France)

N. Breuil (Thales Airborne Systems, 2 avenue Gay-Lussac, Elancourt F-78895, France)

A. Gardelein: Also with Thales Airborne systems, Elancourt, France

T. Razban-Haghighi (Départment Systémes Electroniques et Informatique Industrielle, Université de Nantes, Polytech-Nantes, rue C. Pauc., Nantes 44306, France)

\section{References}

1 Chang, D.H., Erlig, H., Oh, M.-C., Zhang, C., Steier, W.H., Dalton, L.R., and Fetterman, H.R.: 'Time stretching of 102-GHz millimeter waves using novel 1.55-um polymer electro-optic modulator', IEEE Photonics Technol. Lett., 2000, 12, (5), pp. 537-539

2 Liang, J., Levenson, R., Rossier, C., Toussaere, E., Zyss, J., and Rousseau, A.: 'Thermally stable cross-linked polymers for electro-optic applications', J. Phys. III, 1994, 4, pp. 2441-2450

3 Gardelein, A., Le Tacon, S., Tanguy, E., Breuil, N., and Razban, T.: 'Characterization of electro-optic polymer applied to microwave sensing'. Microwave Photonics 2006, October 2006 